\title{
Verification of the Unidimensionality of Academic Delay of Gratification Scale in the Indian Context
}

\author{
Rajib Chakraborty, Dr. Vijay Kumar Chechi
}

\begin{abstract}
The present study verifies the three models on the dimensionality of the construct academic delay of gratification measured with the academic delay of gratification scale prepared by Bembenutty and Karabenick (1996). Sample of the study comprises of 488 professional courses undergraduate students of Muslim minority community (277 boys and 211 girls) from law, engineering, education and pharmacy faculties of Sultan Ul Uloom Education Society, Banjara Hills, Hyderabad, Telangana, India. Exploratory factor analysis was conducted on the responses of the 10 items provided by the sample using SPSS Statistics Ver.23 to extract the factors of the construct. Confirmatory factor analysis conducted using SPSS Amos Ver.23 provided the goodness of fit measures for each of the models. The unidimensional model produced excellent fit indices. Also, one factor model satisfied Gorsuch (1983) criterion to further verify the unidimensional nature of the construct, where the percentage of variance explained by factor 1 was nearly thrice when compared by the percentage of variance explained by the next subsequent factor 2. Monte Carlo principal component analysis method also revealed single factor for this variable. Implications of the findings are discussed.
\end{abstract}

Keywords: Academic Delay of Gratification, Dimensionality, Muslim Minority Community, Professional Courses Undergraduate Students .

\section{INTRODUCTION}

From 1968 to 1974, Dr.Walter Mischel conducted simple but profound experiments called The Delay of Gratification Paradigm, on 4 years old kids from middle class group from Stanford University affiliated nursery school. The test is considered as a gold standard in measuring delay of gratification [30]. According to Mischel, delay of gratification represents "people's attempts to delay immediate smaller gratification for the sake of more desirable but distant goals"[25].

The academic analogue of delay of gratification was defined by Hefer Bembenutty as " willingness to forgo an immediately available option, in favor of a delayed alternative, in order to secure temporarily distant academic rewards, goals, and intentions" [4].

A scale to measure this vital construct of self regulation [24] was constructed by Hefer Bembenutty and Stuart .A. Karabenick consisting of 10 items [3]. The study found that

Revised Version Manuscript Received on April 19, 2019.

Rajib Chakraborty*, Research Scholar, Assistant Professor, School of Education, Lovely Professional University, Phagwara, Punjab, India. rajib.22752@1pu.co.in

Dr. Vijay Kumar Chechi, Professor and HOD, School of Education, Lovely Professional University, Phagwara, Punjab, India.vijay.chechi@1pu.co.in

10 out of the 16 items loaded on a single factor when principal component analysis was applied using varimax rotation on the responses provided by 180 undergraduates.

The six items were removed from the final version of the scale owing to their very low item-total correlation measures [1]. Herndon replicated the study on 319 middle school students to find that the construct was unidimensional in nature [18].

But in a later study, Bembenutty and Karabenick found the scale to be consisting of two dimensions from the responses of 194 undergraduate students[4]. The first factor involved six items $(1,3,4,5,6$ and 8$)$ which made the subject to select a response from academic and non-social alternatives. The second factor consisted of four items (2,7,9 and 10) which made the subject to choose a response between academic and social alternatives. By the end of this study, the authors considered the construct to be unidimensional, in spite of evidences of multi-dimensionality owing to the lack of support from the internal consistency measure for subscales.

\section{REVIEW CRITERIA}

The Spanish adaptation of the scale by Villarroel found the construct to be unidimensional [33]. The Chinese version of the tool prepared by King and Du on 184 undergraduates found the construct to be unidimensional after co-varying the errors of item 1 and item 4 as both the items are framed from the same content of giving up social events [21]. Arabzadeh et.al. conducted psychometric test of the tool on 600 high school students as part its Persian version adaptation and found it to be unidimensional [2].

Ganotice and King tested the global one-factor model with 10 items, the two factor model with items 1,3,4,5,6 and 8 loading on academic and non-social alternative activities factor and items 2,7,9 and 10 items loading on academic and social alternative activities factor, and the three factors model with items 8 and 9 loading on Factor 1 that is academic vs. social alternatives, items 1,3,5,6 loading on the Factor 2 that is academic vs. non-social alternatives and items 2 and 7 loading on Factor 3 that is reversed items [12]. The test was conducted on 425 high school students. The three factor model test showed good fit but the authors settled down with one factor model for parsimony purposes, as Chi-square test between one factor model and two and three factors models showed non-significant results. 
Nakanishi, Nakaya and Nakanishi conducted the Japanese version of the study on 394 Japanese undergraduates and found the construct to be unidimensional [26]. El-Fattah and Salman tested all the three models on 860 high school students while conducting the Egyptian version of the study. They found that the unidimensional structure fitted well when compared to the two factors or the three factors model [1].

Multi-dimensional constructs are conceptualized using the concept of dimensions. [23], [27], [32]. These constructs are either reflective or formative in type. When the relationship, as mentioned in the literature, flows from the construct to its dimensions, the construct is of reflective type or super ordinate type When the relationship flows in the other direction, that is, from the dimensions to the construct, then the type of the construct is formative or aggregate [5], [10]. There are certain constructs which are a mix of reflective and formative types found in Multiple Indicator / Multiple Cause (MIMC) model of structural equation modeling (SEM) [20]. Also, the first step towards development of a theory is to precisely state the relationship between the construct and its dimensions [22]. When there are different versions on the relationship the construct shares with its dimensions, it can lead to arriving at different inferences by the researchers.

\section{RESEARCH OBJECTIVE}

The objective of the present dimensionality verification study is to test the three models on the dimensionality of academic delay of gratification construct, through its academic delay of gratification scale, in the Indian context.

\section{METHOD}

\section{A. Sample}

The present study was conducted by administering the Academic delay of gratification scale on 488 professional courses students, comprising of 277 boys and 211 girls from different professional courses faculties like engineering, law, pharmacy and education of the Sultan Ul Uloom Education Society, a muslim minority educational society located at Banjara Hills, Hyderabad, India.

\section{B. MEASURE:}

Academic Delay of Gratification Scale: The scale consists of 10 items based on immediate or delayed academic experiences. The students respond on a four point Likert scale with responses like "Definitely choose $A=1$, Probably choose $\mathrm{A}=2$, Probably choose $\mathrm{B}=3$, Definitely choose $\mathrm{B}=4$ ". The total score of a student is obtained by adding all the responses and is divided by 10 to get the mean score as the measure of academic delay of gratification. The higher is the mean score between 1 and 4, the greater is the presence of the trait in the subject.

\section{C.PROCEDURE:}

Formal permission was sought and obtained from the Principal of these colleges to administer the tool on the students while the classes were in session. The instructions were explained in details and cooperation was sought from the subjects. The faculty supported in the administration of the test and the students took 10 to15 minutes to complete and handover the tool to the researcher.

\section{D.STATISTICAL TECHNIQUES:}

Exploratory factor analysis was used to reveal the number of factors associated with the construct. Confirmatory factor analysis was used to test for the goodness of fit of the one factor global model, two factors model and the three factors model. Measures like percentage of variance explained by each of the factors, p-value, CMIN/DF, RMR, RMSEA, GFI, IFI, TLI and CFI used in the study. Monte Carlo principal component analysis for parallel analysis is also used to confirm the single dimension construct of this variable which is treated as an accurate method to decide the factors to be retained [34].

\section{V.RESULTS}

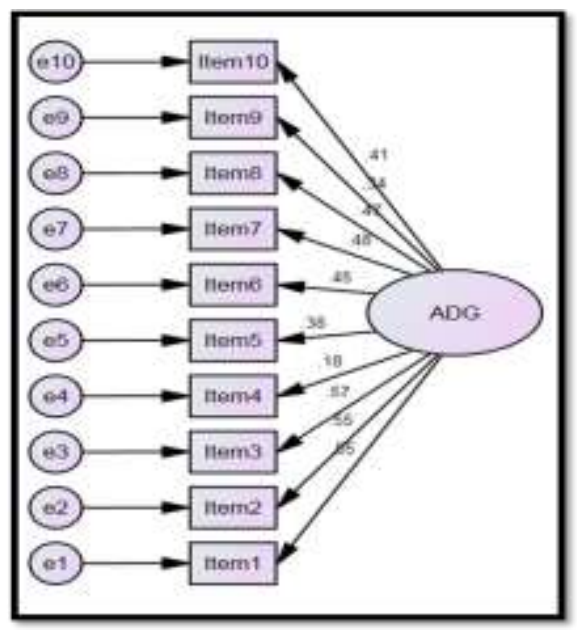

Fig.1. Global One-factor Model:

Table- I: Goodness of Fit for Unidimensional Structure

\begin{tabular}{|l|c|c|c|c|c|c|c|c|}
\hline \multicolumn{1}{|c|}{ Measure } & p-value & CMIN/DF & RMR & RMSEA & GFI & IFI & TLI & CFI \\
\hline Benchmark & $>\mathbf{0 . 0 5}$ & $<\mathbf{3}$ & $<\mathbf{0 . 0 8}$ & $<\mathbf{0 . 0 8}$ & $>\mathbf{0 . 9 3}$ & $>\mathbf{0 . 9 3}$ & $>\mathbf{0 . 9 3}$ & $>\mathbf{0 . 9 3}$ \\
\hline Result & 0.001 & 1.905 & 0.048 & 0.043 & 0.973 & 0.941 & 0.923 & 0.94 \\
\hline
\end{tabular}

Interpretation: The hypothesized unidimensional model of the construct fits well with the pattern of the collected data from the present sample. It is because expect for $\mathrm{p}$-value and 
TLI measures, the obtained results satisfy well the critical benchmark values.

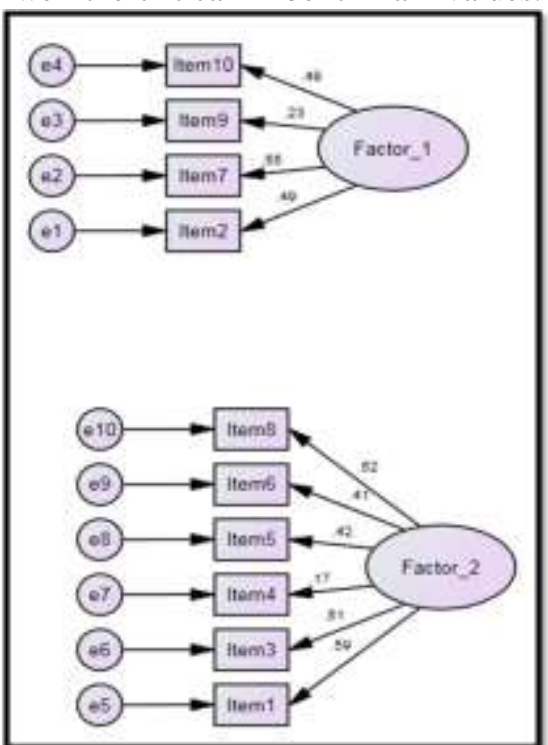

Fig.2 Two-factors Model

\begin{tabular}{|l|c|c|c|c|c|c|c|c|}
\hline Measure & $\begin{array}{c}\text { p-valu } \\
\mathbf{e}\end{array}$ & CMIN/DF & RMR & RMSEA & GFI & IFI & TLI & CFI \\
\hline Benchmark & $>\mathbf{0 . 0 5}$ & $<3$ & $<\mathbf{0 . 0 8}$ & $<\mathbf{0 . 0 8}$ & $\mathbf{> 0 . 9 3}$ & $>\mathbf{0 . 9 3}$ & $>\mathbf{0 . 9 3}$ & $>\mathbf{0 . 9 3}$ \\
\hline Result & 0.000 & 7.206 & 0.173 & 0.113 & 0.919 & 0.596 & 0.471 & 0.589 \\
\hline
\end{tabular}

Table- II: Goodness of Fit for Two Dimensional Structure

below the benchmark. It means that this model does not fit

Interpretation: All the goodness of fit indices results of the well at all with the pattern of the collected data. two factors / dimensions model are either well above or well

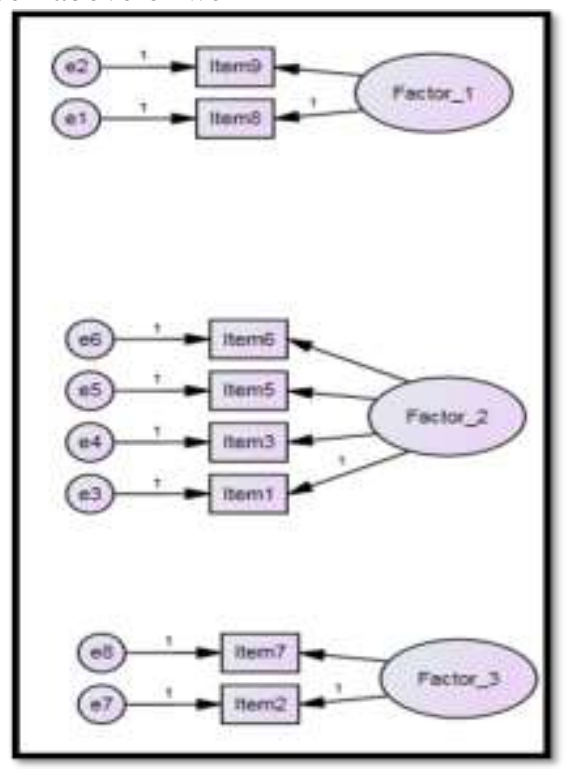

Fig. 3 Three-factors Model

\begin{tabular}{|c|c|c|c|c|c|c|c|c|}
\hline Measure & p-value & CMIN/DF & RMR & RMSEA & GFI & IFI & TLI & CFI \\
\hline Benchmark & $>0.05$ & $<3$ & $<0.08$ & $<0.08$ & $>0.93$ & $>0.93$ & $>0.93$ & $>0.93$ \\
\hline Result & 0.000 & 16.957 & 0.000 & 0.181 & 1.000 & 1.000 & - & 1.000 \\
\hline
\end{tabular}

Table- III: Goodness of Fit for Three Dimensional Structure 
Interpretation: All the goodness of fit indices results of the three factors model are either well above or well below the benchmark. It means that this model does not fit well at all with the pattern of the collected data. No factor loadings for the present model was obtained through confirmatory factor analysis.

\begin{tabular}{|c|c|c|}
\hline S.No. & Factor & $\begin{array}{c}\text { Explained } \\
\text { Variance } \\
\text { Percentage }\end{array}$ \\
\hline 1. & Factor 1 & 28.133 \\
\hline 2. & Factor 2 & 10.518 \\
\hline 3. & Factor 3 & 10.320 \\
\hline
\end{tabular}

Table - IV: Percentage of Variance Explained by the Factors Extracted through EFA

Interpretation: According to Gorsuch, if the percentage of variance explained by factor 1 is nearly thrice when compared to the percentage of variance explained by the next subsequent factor 2, the construct can be considered to be unidimensional [11]. Here, the factor 1 explained 28.133 percentage of the construct while factor 2 could manage to explain $10.518 \%$ of the construct only. The first factor's variance percentage is almost thrice of the second factor's variance, indicating that the global one-factor model of academic delay of gratification holds good in Indian undergraduate students sample.

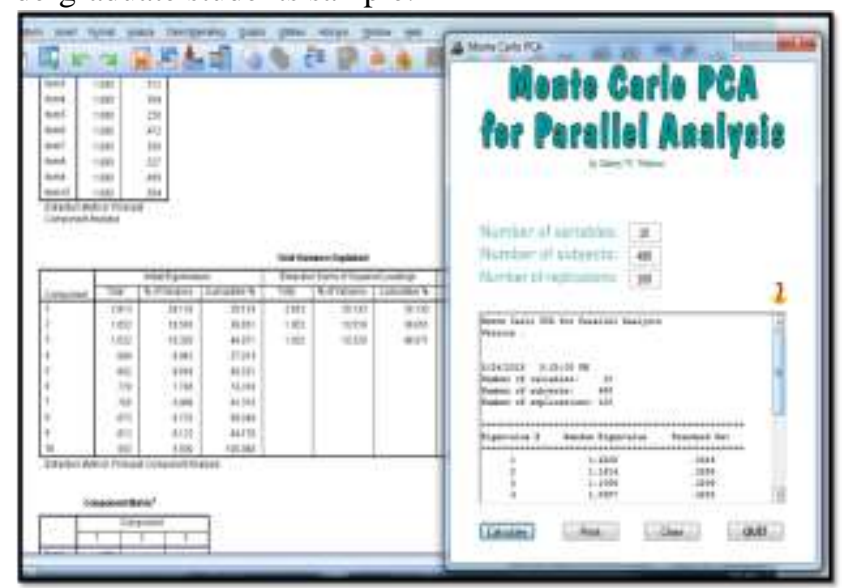

Fig. 4 Monte Carlo Principal Component Parallel Analysis

Interpretation: Exploratory factor analysis, using principal axis factoring extraction method and varimax rotation produced three factors with eigen values $2.813,1.052$ and 1.032 respectively. Monte Carlo principal component analysis for parallel analysis method generated certain randomly eigen values for 100 iterations. These randomly generated eigen values can be treated as critical eigen values.

The factors produced through exploratory factor analysis by SPSS Statistics, whose eigen values are greater than the critical eigen values must be retained. Only the first factor has an eigen value of 2.813 which is greater than the first critical eigen value 1.2208. The rest of the two factors from EFA have eigen values less than the randomly generated critical eigen value from Monte Carlo PCA parallel analysis software for
100 iterations. The eigen value of the second factor extracted was 1.052 which is less than the second random eigen value 1.1614 of parallel analysis. This result itself confirms the unidimenisionality of the academic delay of gratification construct.

\section{RESULT AND DISCUSSION}

The scale prepared to measure academic delay of gratification construct by Bembenutty and Karabenick is validated in different cultures across the world and the authors do report the factor structure of this construct as part of its psychometric properties. Most of the studies reported the variable to be one-factor in nature. But, in spite of evidences of multi-dimensionality found in some studies using factor analysis, including the one involving the authors of the original tool themselves, most of the authors report the construct to be unidimensional for parsimony purposes.

In one of the previous studies on this construct in the Indian context, the authors found acceptable psychometric properties of the variable but found it to be scalar variant along with unidimenisonality [5]. The present study tried to verify the three models of the factor structure of academic delay of gratification construct found in its literature, in the Indian context. Here, in addition to applying the statistical techniques of exploratory and confirmatory factor analysis, the authors tried to justify the unidimensionality of the construct using Gorsuch's criterion and comparing the extracted factor's eigen values from SPSS Statistics software with the randomly generated eigen values of Monte Carlo PCA for parallel analysis software.

While the one-factor structure produced excellent goodness of fit indices and almost satisfied Gorsuch's criteria, the two factors model and three factors model provided very poor fit measures for the present sample study. The eigen value of the first extracted factor was greater than the randomly generated eigen value for 100 iterations, and hence it was only retained. In the light of these additional evidences, the academic delay of gratification construct can be considered to be unidimensional.

With respect to the limitations of the study, the subjects of the sample represent the largest minority in a culturally diverse country like India and not its majority populace. Also, though the sample belonged to the Hyderabad city of India where the muslim minority is well concentrated, members of this community are spread all over the country and further studies must be conducted over larger sample sizes covering undergraduates from this minority community from other regions of the country. Finally, there is a need to replicate this study in undergraduate student samples belonging to other cultures of India.

\section{CONCLUSION}

A construct is multidimensional when it indicates towards many separate but related dimensions representing a single theoretical concept [23]. 
A unidimensional construct represents a single theoretical concept [14]. The researchers who support the utility of multidimensional concepts say that such construct represent a complex phenomena completely [16], [17], [27], [29]. But, those who debate on the opposite side, argue that such constructs suffer from confounding influences of the dimensions and explain less variance when compared their dimensions [13], [14], [19], [28], [32].

This debate has been going on for a long time without any signs of stopping [6], [31], [9]. The present study tried to bring clarity in this context, on the topic of verification of dimensionality or factor structure of academic delay of gratification construct in the Indian context and verified the same in more than one ways. The unidimenisonality of the construct is established. The two-factors model and three factors models are rejected in the Indian context owing to their poor goodness of fit measures, not meeting Gorsuch's criterion and failing Monte Carlo principal component analysis for parallel analysis test. However, these results are subject to the condition that further replication studies are warranted.

\section{REFERENCES}

1. S.M. Abd-El-Fattah, A.M. Salman, Academic Delay of Gratification: A Construct Validation with High School Students. J Psychol Clin Psychiatry 8(1): 00472. DOI: 10.15406/jpcpy.2017.08.00472, 2017.

2. M. Arabzadeh, P. Kadivar,, A. Delavar, J. Kavousian, Reliability, validity, and factor analysis of the Persian Academic Delay of Gratification Scale. Interdisciplinary Journal of Contemporary Research in Business 4(2): 571-579, 2012.

3. H.Bembenutty, \& S.A. Karabenick, Academic Delay of Gratification Scale: A new of measurement of delay of gratification. Paper presented at the Eastern Psychological Association, USA, pp. 1-11, 1996.

4. H. Bembenutty, \& S.A. Karabenick, “Academic Delay of Gratification", Learning and Individual Difference, Volume 10, Number 4, 1998, pages 329-346, ISSN: 1041-6080, 1998.

5. K. Bollen, \& R. Lennox, Conventional wisdom on measurement: A structural equation perspective. Psychological Bulletin, 110, 305-314, 1991.

6. R.B.Cattell, \& B. Tsujioka, The importance of factor-trueness and validity, versus homogeneity and orthogonality, in test scales. Educational and Psychological Measurement, 24, 3-30, 1964.

7. R. Chakraborty, Validation of Academic Delay of Gratification Scale among Indian Professional Courses Students, International Journal of Indian Psychology, Volume 4, Issue 2, No. 92, ISSN:2348-5396 (e), ISSN:2349-3429 (p), DIP:18.01.117/20170402, ISBN:978-1-365-78192-6, 2017.

8. S.Cassidy, The Academic Resilience Scale (ARS-30): A New Multidimensional Construct Measure, Front. Psychol., 7:1787. doi: 10.3389/fpsyg.2016.01787, 2016.

9. J.R. Edwards, Multidimenisonal constructs in organizational behavior research: An integrative analytical framework, Organizational Research Methods, Vol. 4 No. 2, 144-192, 2001.

10. .J.R.Edwards, \& R.P. Bagozzi, On the nature and direction of the relationship between constructs and measures. Psychological Methods, 5, 155-174, 2000.

11. R.L.Gorsuch,. Factor Analysis, 2nd Edn. Hillsdale, NJ: Erlbaum, 1983.
12. F.A.Ganotice, \& R.B.King,. Blessed are Those Who Wait: Validating the Filipino Version of the Academic Delay of Gratification Scale (ADOGS). The Asia-Pacific Education Researcher 23(1): 19-27, 2014.

13. D.W. Gerbing, \& J.C.Anderson, An updated paradigm for scale development incorporating unidimensionality and its assessment. Journal of Marketing Research, 25, 186-192, 1998.

14. J. Hattie, Methodology review: Assessing unidimensionality of tests and items. Applied Psychological Measurement, 9, 139-164, 1985.

15. L.G.Humphreys, The organization of human abilities. American Psychologist, 17, 475-483, 1962.

16. K.A. Hanisch, C.L.Hulin, \& M. Roznowski, The importance of individuals' repertoires of behaviors: The scientific appropriateness of studying multiple behaviors and general attitudes. Journal of Organizational Behavior, 19, 463-480, 1998

17. C.L. Hulin, C. L.. Adaptation, persistence, and commitment in organizations. In M. D. Dunnette \& L. M. Hough (Eds.), Handbook of industrial and organizational psychology (2nd ed., pp. 445-505). Palo Alto, CA: Consulting Psychologists Press, 1991.

18. J.S. Herndon, The effects of delay of gratification on the academic achievement, substance abuse, and violent behavior of middle school students in alternative learning settings. Unpublished doctoral dissertation, University of Central Florida, USA, 2011.

19. G..Johns, . Aggregation or aggravation? The relative merits of a broad withdrawal construct. Journal of Organizational Behavior, 19, 453-462, 1998.

20. K.G.Jöreskog, \& A.S.Goldberger, Estimation of a model with multiple indicators and multiple causes of a single latent variable. Journal of the American Statistical Association, 10, 631-639, 1975.

21. R.B.King,, \& H. Du, All good things come to those who wait: Validating the Chinese version of the Academic Delay of Gratification Scale (ADOGS). The International Journal of Educational and Psychological Assessment 7(1): 64-80, 2011.

22. K.S. Law, \& C.S.Wong,. Multidimensional constructs in structural equation analysis: An illustration using the job perception and job satisfaction constructs. Journal of Management, 25(2): 143-160, 1999.

23. K.S.Law, C.S.Wong, \& W.H. Mobley, Toward a taxonomy of multidimensional constructs. Academy of Management Review, 23, 741-755, 1998.

24. J. Metcalfe, \& W. Mischel, W. A hot/cool-system analysis of delay of gratification: dynamics of willpower. Psychol Rev; 106:3-19, 1999.

25. W. Mischel, Metacognition and rules of delay of gratification. In J. H.Flabell \& L. Ross (Eds.), Social cognitive development: Frontiers and possible futures, NY: Cambridge University Press, 1981.

26. M. Nakanishi, M. Nakaya, Y. Nakanishi., Development of the Japanese Version of the Academic Delay of Grati-cation Scale for Undergraduate Students, The Japanese Journal of Personality, Vol. 23 No. 3, 197-200, 2015.

27..D.S. Ones, \& C. Viswesvaran,. Bandwidth-fidelity dilemma in personality measurement for personnel selection. Journal of Organizational Behavior, 17, 609-626, 1996 
28. S.V. Paunonen, M. G. Rothstein, \& D.N. Jackson. Narrow reasoning about the use of broad personality measures for personnel selection. Journal of Organizational Behavior, 20, 389-405, 1999.

29. M. Roznowski, \& K. A. Hanisch, Building systematic heterogeneity into work attitudes and behavior measures. Journal of Vocational Behavior, 36, 361-375, 1990.

30. .P.K.Saxler, The Marshmallow Test: Delay of Gratification and Independent Rule Compliance. Doctoral dissertation, Harvard Graduate School of Education, (2016).

31. F.L..Schmidt, \& L. B. Kaplan, Composite vs. multiple criteria: A review and resolution of the controversy. Personnel Psychology, 24, 419-434, 1971.

32. R. J. Schneider, L. M .Hough, \& M. D. Dunnette, Broadsided by broad traits: How to sink science in five dimensions or less. Journal of Organizational Behavior, 17, 639-655, 1996.

33..J.R.Villarroel, An examination of the psychometric properties of the Spanish version of the Academic Delay of Gratification Scale. Advances in Applied Developmental Psychology 2: 156-167, 2008.

34..W.F.Velicer, \&\& D.N. Jackson, "Component Analysis Versus Common Factor Analysis - Some Future Observations", Multivariate Behavioral Research, 25(1), 97-114,1990 